\title{
Debates científicos e a produção do vinho paulista, 1890-1930
}

Scientific debates and the production of the São Paulo wine, 1890-1930

Graciela de Souza Oliver*

\section{RESUMO}

Este artigo apresenta o contexto histórico do surgimento da vitivinicultura paulista e a maneira como as publicações científicas caracterizaram essa produção. Por meio da leitura dos Boletins do Instituto Agronômico de Campinas, do Boletim da Agricultura, dos livretos de Pereira Barreto (1840-1923) e das revistas Chácaras e Quintaes, O Campo e Revista Agrícola identifico os fatores que motivaram o desenvolvimento dessa cultura. Na criação dos conceitos de vinhos artesanais, vinhos falsificados e vinhos regulados nota-se a influência tanto das teorias científicas modernas como de ideais do pensamento social da época. Mesmo não sendo possível mostrar o impacto econômico dessas publicações, nota-se a criação de um debate científico, com seus tópicos e demandas. A manutenção dessa cultura científica serviu também de motivação para o desenvolvimento de outras pesquisas num momento seguinte.

Palavras-chave: história da divulgação científica; instituições científicas; história da vitivinicultura paulista.

\section{ABSTRACT}

The paper presents the historical context of wine production in São Paulo and how scientific publications characterized it. Through the reading of Boletins do Instituto Agronômico de Campinas, Boletim da Agricultura, booklets by Pereira Barreto (1840-1923), Chácaras e Quintaes, O Campo e Revista Agrícola I identify the factors that influenced its development. Influences from modern scientific theories and social ideals were noted on the construction of the terms: artesian wine, false wine and regular wine. Although it is not possible to say what economic impacts those publications had on the development of São Paulo's wine production, we can show a scientific debate, its topics and demands. This debate subsequently contributed to the foundations of other scientific researches.

Keywords: history of scientific literacy; scientific institutions; history of grapevine agriculture of São Paulo.

\footnotetext{
* Programa de Pós-Graduação em História, Faculdade de Filosofia e Ciências Humanas, Universidade Federal de Minas Gerais (UFMG). Av. Antonio Carlos, 6627, Campus Universitário. 31270-901 Belo Horizonte - MG - Brasil. gracioliver@gmail.com.
} 
Falar a respeito da produção de vinho ou da viticultura em São Paulo é talvez um assunto pouco comum na historiografia. Sérgio Buarque de Holanda nada menciona a respeito em seu livro sobre as técnicas empreendidas na cidade de São Paulo até o início do século XIX. Dos trabalhos realizados no âmbito dos cursos de pós-graduação em História, nas décadas de 1970 e 1980, de viés marxista, nenhum estudo buscou focalizar a temática.

No caso do estudo de Sérgio Buarque de Holanda, compreende-se essa ausência pelos objetivos traçados pelo autor. Em Caminhos e fronteiras ele valoriza a originalidade de algumas técnicas criadas por aqui, ou aquelas que sofreram adaptações, com o objetivo de identificar o processo de aculturação dos portugueses. Nesse processo, os saberes para a produção de vinho, tão tradicionais da cultura metropolitana, não tiveram relevância social na adaptação ao novo ambiente.

Recentemente, alguns historiadores têm feito releituras tanto de fontes primárias como de secundárias, buscando as práticas alimentares dos diferentes períodos e grupos culturais. O estudo realizado por Ricardo Souza ${ }^{1}$ sobre o consumo de bebidas alcoólicas apresenta esse viés, fazendo notar uma intensa produção de vinhos em São Paulo no início da colonização. Essa produção teria sido proibida para não afetar o comércio metropolitano em meados do século XVII. O autor revela ainda o aumento da importação de vinhos em São Paulo em fins do século XIX e a presença de vinhos finos (madeira ou xerez e franceses) em manuais de boas maneiras. Por fim, considera que aos ricos cabia um vinho de maior teor alcoólico, enquanto aos pobres, os vinhos mais fracos ou "falsificados", os quais muitas vezes eram vinculados ao alcoolismo.

No âmbito dos estudos de história econômica, nas décadas de 1970 e 1980, a produção vitivinícola paulista não foi enfocada por razões metodológicas. O trabalho de José Tavares dos Santos² constitui exceção, mas não se aplica ao caso paulista. Nesse estudo, o autor procurou entender as condições sociais de produção de vinhos nas colônias italianas do sul do país. Interessava ao autor compreender quando aquela produção tornou-se fator essencial para a reprodução social camponesa, detalhando suas fases e as conseqüências culturais e sociais daquela produção.

No caso paulista, os vinhos eram intensamente importados e sua produção interna era comercialmente insignificante, não havendo razões para se debruçar sobre essa produção específica, a não ser como mais uma das atividades dos imigrantes. Conseqüentemente, têm surgido estudos sobre essa 
produção como parte do processo de diversificação da agricultura e de formação tanto do complexo cafeeiro como de um mercado interno.

O estudo de Rosane Monteiro ${ }^{3}$ trata da diversificação econômica nas fazendas de Araraquara e de São Carlos entre fins do século XIX e início do século XX. A autora focaliza as chamadas "fazendas mistas", salientando a permanência da produção para exportação, conjunta à produção para o mercado interno. Em Araraquara, a propriedade do italiano Vicente Puchanti - Propriedade Agrícola Etruria - foi considerada como exemplo desse tipo de fazenda. Nela produziam-se, além do café, frutas, aspargos, árvores de ornamentação e essências florestais, bem como mudas para a formação de pomares, hortas, bosques e jardins. Além disso, a Etruria vendia uvas de mesa e fabricava vinhos com uvas européias. Em São Carlos, a autora apenas indica a existência da fábrica de vinhos de Bernardo Colecte em fins do século XIX.

Dado o enfoque utilizado neste estudo, compreendemos o contexto econômico em que se inseria a produção de vinhos, mas pouco sobre as características específicas da produção em si. Os trabalhos de Lia Romero ${ }^{4}$ cobrem essa lacuna. Tomando como documentação grande número de periódicos de divulgação científica para a agricultura, ela caracteriza a produção vitivinícola dentro do complexo econômico cafeeiro, mostrando o crescimento quantitativo dessa produção entre 1886 e 1926. Aponta a diversidade de variedades plantadas, relatando quais membros da elite ilustrada paulista se dedicaram à vitivinicultura e expondo o papel desempenhado pelas exposições nacionais na divulgação de novas técnicas agrícolas. Por último, descreve as técnicas agrícolas e industriais utilizadas pelos agricultores.

Contudo, ressentimos uma leitura mais crítica da documentação, principalmente aquela resultante da atividade científica ou a ela pertinente. Em seu estudo lemos sobre uma ciência destacada da sociedade, que conduz impreterivelmente ao progresso e cujo discurso sobre a sociedade é tido como descrição neutra do passado. Tal visão sobre a ciência compreende que o conhecimento científico desenvolve-se por leis próprias, recebendo influências sociais apenas em suas formas de organização. Na historiografia atual da História das Ciências, em especial aquela que focaliza o processo de institucionalização científica, contexto e conteúdo são abordados de forma a fazer notar 'a ciência' também como uma produção social e da cultura local. ${ }^{5}$

Antes do estudo de Lia Romero, quem mais se dedicou ao levantamento histórico da produção vitivinícola paulista, ainda que amparado numa história política e determinista, foi o engenheiro agrônomo Júlio Inglez de Souza. Ele trabalhou entre 1948 e 1964 na Estação Experimental de Jundiaí com a 
produção de novas variedades de uvas e práticas culturais para o melhoramento da vitivinicultura. Em Origens do vinhedo paulista (1959) e em Uvas para o Brasil (1969), além das condições próprias de solo e de clima, o autor menciona como prerrogativa para o surgimento daquela cultura certo grau de sedentarismo da sociedade. E, embora não cite Sérgio Buarque de Holanda, seus argumentos corroboram a interpretação daquele historiador, levando-nos a caracterizar o hiato da produção vitivinícola entre os séculos XVII e XIX.

Em Uvas para o Brasil, o motivo para o impulso vitivinícola paulista no século XIX foi vinculado à introdução de variedades nativas da América do Norte. Uma destas, a variedade de videira Isabel (Vitis labrusca), teria chegado a São Paulo pelas mãos do inglês John Rudge. Para Júlio Inglez de Souza, com o fim da escravidão e o ingresso do imigrante italiano, a viticultura teria se estabelecido de forma compensadora, uma vez que essa produção estava arraigada à sua cultura. Em seus textos percebemos a relação causal entre a constituição da nação, de seu povo e da cultura civilizada. Para a confecção de seus trabalhos, aquele agrônomo apoiou-se na leitura dos trabalhos do médico e viticultor paulista Pereira Barreto (1840-1923), nos trabalhos científicos publicados a partir de 1870 e no relato de alguns viajantes.

Ainda segundo aquele autor, entre os anos de 1830 e 1840 o cultivo da videira Isabel teria se esparramado pelos quintais urbanos e chácaras suburbanas, nos bairros periféricos da capital e em Mogi das Cruzes, acrescidos com o tempo das localidades de São Roque e Jundiaí. Nesses lugares, até o início do século XX, a uva teria sido usada tanto para consumo in natura como para a fabricação de vinhos, que o autor não chegou a quantificar. Mas quais outros aspectos teriam propiciado o aumento dessa atividade? Por que interessava ao discurso científico notificar essa produção? Se economicamente era mínima, que outras abordagens podem nos ajudar a caracterizar a produção de uvas e vinhos no início do século XX no estado de São Paulo? Nessas questões nos detemos no presente artigo, algumas das quais parcialmente desenvolvidas em pesquisa e comunicação anteriores. ${ }^{6}$

\section{EXPANSÃO E CONTRAÇÃO DA VITIVINICULTURA PAULISTA}

Em meados do século XIX produziram-se uvas e possivelmente vinhos nas cidades a partir das quais teve início a ocupação do solo paulista. Trata-se das cercanias de São Paulo (Itu, Mogi das Cruzes, Sorocaba) e das cidades fronteiriças ao estado de Minas Gerais, ou próximas às cidades de Pouso Ale- 
gre e Andradas. Nesses três principais pontos, a fabricação foi estritamente artesanal e de propriedade de grandes fazendeiros que consumiam o vinho particularmente e em ocasiões especiais. Isso é o que podemos observar na leitura de viajantes como Max Leclerc (1864-1932), Augusto Emílio Zaluar (1826-1882) e Jean Baptiste Debret (1768-1848).

No relato do viajante Daniel Parish Kidder (1815-1891), quando visitou as províncias de São Paulo e do Rio de Janeiro em meados da década de 1830, encontramos descrições sobre esse consumo e o seu valor: "Foi-nos então servido vinho paulistano, puro suco de uvas cultivadas na fazenda, e que, segundo opinião dos entendidos, era de fina qualidade"? Trata-se de vinho artesanal, porque feito de forma empírica de acordo com as tradições de seu produtor. O termo 'batalha' é freqüente quando se trata dessa produção.

Até que outros estudos se aprofundem no assunto, buscando as relações entre o saber popular e o saber científico daquele momento, podemos dizer que não se dispunha de explicações científicas modernas para o fato de um vinho estragar-se ou resultar excelente. Assim, além do saber tradicional, compreende-se que o tamanho dessas produções teria sido regulado pelo tamanho do parreiral, dos barris de madeira ou das dornas de fermentação, dependendo também da construção de cantinas e da disposição de veículos que transportassem tonéis de 25 litros (quartola), 80 litros (quinto) e 400 a 500 litros (pipa).

Sendo representante de uma tradição européia e cristã, a produção nacional de vinho trazia status ao seu produtor, ainda mais se o produto fosse referendado pela palavra de especialistas ou por sua possível fama local. Entretanto, o consumo de vinhos era majoritariamente dado pela importação de vinhos comuns, ou vinhos inferiores: vermutes, conhaques, vinhos de outras frutas, licores e vinhos não especificados. Esses vinhos eram bem vendidos nas hospedarias dos principais caminhos entre os estados de São Paulo, Minas Gerais e Rio de Janeiro.

Com o início da segunda marcha de expansão do café, atingindo Ribeirão Preto e Jaboticabal no início do século XX, com a imigração subsidiada e a construção das ferrovias, observa-se o aumento das localidades vitivinícolas. Na leitura dos periódicos científicos foi possível identificar a produção de vinhos nas seguintes cidades, entre 1880 e 1900: Batatais, Boituva, Caconde, Campinas, Capivari, Cunha, Espírito Santo do Pinhal, Itaici, Itapeva, Itapira, Itatiba, Jaboticabal, Jundiaí, Limeira, Matão, Mogi das Cruzes, Nova Europa (núcleo Gavião Peixoto), Paraíso, Pirassununga, Pirituba, Ribeirão Preto, Rio 
Claro, Sabaúna, Santa Ernestina, São Bernardo, São João da Boa Vista, São Paulo, São Roque, Sorocaba e Tietê.

As cidades destacadas não chegam a constituir um agrupamento único, podendo ser distinguidas da seguinte maneira: 1) Acompanham o traçado de três principais ferrovias: Mogiana, Paulista e Sorocabana; 2) conseqüentemente, são cidades cafeicultoras importantes ou próximas a elas; e 3) algumas são fronteiriças ao estado de Minas Gerais. Sobre isso, convém lembrar o trabalho de Pierre Monbeig ${ }^{8}$ quando destaca a rápida conquista do solo por parte de mineiros, que partiram em busca de novas terras para as plantações de café. No território mineiro, prevaleciam as variedades provenientes de Portugal, do Algarve e da Madeira, como a dedo-de-dama, a moscatel e a ferral (Vitis vinifera L.), sendo difícil precisar qual teria sido o percurso das variedades americanas entre os dois estados a partir de fins do século XIX.

Nesse novo contexto de expansão da viticultura, o consumo e a produção de vinho tornaram-se uma necessidade, na opinião das elites paulistas. Impulsionado possivelmente pelas discussões médico-higienistas de fins do século XIX, o vinho ganhará destaque como um alimento das civilizações avançadas em detrimento da cachaça, que remetia ao passado colonial, salientando as distinções sociais existentes e fazendo aumentar seu consumo. A defesa do vinho como uma bebida saudável esteve vinculada ao desenvolvimento das teorias humorais, o que posteriormente foi retomado e trabalhado por Louis Pasteur, quando publicou sua teoria dos microrganismos, em fins do século XIX. ${ }^{9}$

No Brasil, trabalhos sobre microrganismos ganharam destaque na Faculdade de Medicina do Rio de Janeiro, ainda na década de 1880, e no Instituto Bacteriológico de São Paulo. ${ }^{10}$ Segundo Gilberto Hochman, ${ }^{11}$ uma das matrizes do pensamento social brasileiro nasceu das discussões médicohigienistas que buscavam na ciência a solução para as mazelas do país. As ações em saúde pública resultantes desse pensamento foram consideradas como parte da formação do Estado brasileiro e não como um simples reflexo das demandas urbanas e econômicas da época. Em São Paulo, tais debates chegaram a se consolidar em torno de um grupo e em periódicos definidos, buscando enfatizar a liderança paulista no progresso da nação. ${ }^{12}$

O discurso de Pereira Barreto pode ser compreendido dentro desse referencial. Desde fins do século XIX, esteve envolvido no processo de institucionalização da medicina em São Paulo, ${ }^{13}$ sendo um dos primeiros diretores da Sociedade de Medicina e Cirurgia de São Paulo (1888), membro do Partido Republicano Paulista e um dos fundadores do positivismo paulista. Partici- 
pou das discussões sobre as epidemias que assolavam São Paulo, publicando diversos artigos sobre a febre amarela nos jornais Commercio de S. Paulo e O Estado de S. Paulo.

Nessa mesma época, em 1888, Pereira Barreto mandou a Victor Pulliat, famoso ampelógrafo francês, cachos de uvas colhidos em sua chácara em Pirituba, das mesmas variedades então plantadas na Europa. Os dados de suas experiências também foram publicados no jornal La Vigne Americana, o que vinha contribuir para uma propaganda positiva da agricultura e das terras brasileiras no exterior.

Para Pereira Barreto a vitivinicultura poderia garantir a fixação dos imigrantes. $\mathrm{O}$ vinho era proposto como uma alternativa a outras bebidas como a cachaça e também às frutas tropicais:"E, na falta de sadias e sazonadas frutas, essas pobres inocentes (moças finas) atiram-se sobre os milhos verdes e as nefastas melancias, que as prostram no leito quando não as fazem baixar ao túmulo!”. ${ }^{14}$ Essas observações e conclusões eram fruto de sua preocupação como médico formado na Bélgica (Universidade de Bruxelas), tendo validado seu diploma pela Escola de Medicina do Rio de Janeiro, com a defesa da tese “Teoria das gastralgias e neuroses em geral”, em 1865.

Paralelamente a isso, no período pós-1870, quando se deu a fundação de diversas instituições científicas, a crença de que a ciência traria o progresso e resolveria os problemas que ameaçavam a expansão cafeeira era um dos principais ideais ventilados na imprensa paulistana em geral, tanto em seus diários como em periódicos especializados. Diversas lideranças da comunidade científica em geral também buscavam expressar suas convicções, concepções e estratégias de ação, tanto para o público em geral como para o Estado, buscando com isso alertá-lo e legitimar o papel da ciência e dos cientistas na construção da civilização. ${ }^{15}$

No tema da vitivinicultura, entretanto, Pereira Barreto publicou mais em folhetos independentes do que em jornais e periódicos especializados. Em 1896 publicou A vinha e a civilização, e, em 1900, A arte de fabricar o vinho Manual do Viticultor e A vinificação moderna. Na Revista Agrícola, publicou "A viticultura no Brasil", em 1896, e no Boletim da Agricultura publicou "A viticultura em São Paulo", em 1905. Tais textos foram tomados constantemente como referências até o início da década de 1930, nos artigos científicos que consultei.

As publicações de Luís Pereira Barreto tinham como público alvo os pesquisadores do Instituto Agronômico de Campinas, os principais fazendeiros de café e os colonos. Nota-se verdadeira animação em torno da vitivinicultura 
em fins do século XIX. Em documento sobre as condições adotadas no contrato dos colonos de 1888 em Campinas, era possível este receber um lote de $2.000 \mathrm{~m}^{2}$ plantado com videiras novas. E, como remuneração dos trabalhos que devia fazer, tinha o direito de mais $500 \mathrm{~m}^{2}$ por pessoa se houvesse plantado cereais, cafezais novos ou videiras novas. No artigo 11 do documento citado consta: "Receberá por cada capina de um alqueire plantado em videiras, a importância de $20 \$ 000$ e por 50 litros de uva, a quantia de 100 réis". ${ }^{16} \mathrm{O}$ destino dessas uvas tanto podia ser a venda como fruta ou a prensa em uma cantina própria dos colonos ou da fazenda.

Entretanto, de acordo com o que salientavam diversos artigos da época, a viticultura exigia tantos cuidados como o café. Necessitava de podas especiais, capinas constantes e vigílias contra ataques de animais, insetos e doenças, sem contar com os serviços de cantina, para a preparação do vinho, sendo facilmente deixada de lado.

Mesmo assim, a partir de 1910 e até 1920, observa-se um aumento de cidades que têm alguma produção de vinhos. Esse impulso resultou da expansão cafeeira e dos processos de expansão agrícola e demográfica. Nota-se um aumento mais quantitativo do que qualitativo em algumas regiões já destacadas anteriormente, como nas cidades que acompanham a linha férrea da Mogiana e da Sorocabana e ao longo de novos ramais, como na região da Alta Sorocabana, do Vale do Paraíba e nas extensões da Estrada de Ferro Paulista na altura de Jaú e de Capivari. Contudo, as cidades com maior produção continuavam sendo aquelas iniciais como Campinas, Itatiba, Itu, Jundiaí, Mogi das Cruzes, São Bernardo, São João da Boa Vista, São Roque e Tietê.

É nesses lugares que a vitivinicultura ganhou maior destaque na economia regional, tomando o lugar das antigas plantações de café. Contudo, com a exceção de alguns dados estatísticos para a produção de vinhos no núcleo colonial de São Caetano em fins do século XIX, indicados por Lia Romero, e de alguns dados sobre núcleos de Barão de Jundiaí, de Parnaíba, Gavião Peixoto e Jorge Tibiriçá nas estatísticas agrícolas do estado de São Paulo, de 1915 e 1920, nada podemos dizer sobre a produtividade da região.

Há que se considerar que o vinho produzido pelos colonos, ainda que em maiores quantidades, não passava pela fiscalização ou possivelmente era consumido in loco. Podemos destacar ainda que, por ser pouco influente na economia, a produção vitivinícola paulista como um todo não se mostra em outras fontes documentais oficiais. Isto ocorre, por exemplo, ao relacionar nomes de fazendeiros campineiros, citados nos Boletins do Instituto Agronômico como vinicultores, com registros judiciais. Neste trabalho não foi possível localizar a posse de instrumentos, livros, de uma adega, cantina ou vinhedo em in- 
ventários da comarca de Jundiaí, por exemplo, para os nomes de Antônio Álvaro de Souza Camargo e Miguel de Abreu Pereira Coutinho, citados respectivamente em 1904 e 1909 nos Boletins do Instituto Agronômico de Campinas.

Desse modo, para esse primeiro período é possível caracterizar tanto uma expansão como uma tendência à concentração da área vitivinícola, voltada para o atendimento dos dois centros urbanos da época - Campinas e São Paulo. Notamos o início do que Júlio Inglez de Souza caracterizaria posteriormente como o "polígono da viticultura paulista", compreendido entre as cidades de Ibiúna, Valinhos, Morungaba, Bragança Paulista e Mogi das Cruzes. Assim, para a vitivinicultura a imigração trará três novos elementos, nesta seqüência: 1) a produção em pequena propriedade localizada ao redor das sedes das fazendas; 2) um aumento na demanda de vinhos; e 3 ) o direcionamento da produção aos maiores mercados urbanos, como Campinas e São Paulo. E este último elemento também pode ser compreendido pela preferência dos imigrantes pelo meio urbano, configurando um terceiro momento de conceituação dos vinhos paulistas, como veremos mais adiante. Mesmo assim, na literatura consultada havia grande animação em torno da fabricação do vinho nacional, cujas técnicas modernas se incumbiria o Instituto Agronômico de Campinas de difundir.

\section{O VINHO SOB A LENTE CIENTÍFICA: DO VINHO ARTESANAL AO FALSIFICADO}

A falta do vinho é uma grave lacuna, e enquanto ela subsistir, a nossa imigração andará forçosamente manca; não será vencida no coração do colono a tendência de voltar para a sua pátria...

Barreto, 1900a, p.7

Para Pereira Barreto só a viticultura e o vinho eram capazes de fixar o imigrante espontaneamente por aqui. A vitivinicultura traria a independência ao cultivo do café, a solução definitiva para a falta de braços, cuja imigração Estado e fazendeiros subsidiavam. Além disso, traria valores. O autor via o imigrante como "um homem em cujo peito bate um coração, e nesse coração muitas vezes se aninha uma tenaz propensão para a poesia” (ibidem). A defesa da viticultura como apoio à imigração é uma resposta ao medo de ver a lavoura desamparada e dependente somente do braço nacional. Era preciso portanto criar vínculos culturais.

Buscavam divulgar a vitivinicultura dentro do discurso do trabalho co- 
mo criador de uma nova moral: “A primeira riqueza de um país é a população: é dela que dependem as outras riquezas ... devemos oferecer ao imigrante todas as melhores condições, quer materiais, quer sociais e morais..." (ibidem). Desse trecho inferimos que a maioria dos trabalhadores não imigrantes, a qual bebe as "zurrapas e beberagens" sem reclamar, estaria simplesmente ocupando espaço. Na visão daqueles que incentivam a vitivinicultura, todas essas pessoas juntas não foram capazes de desenvolver uma cultura, "um povo".

Era preciso, portanto, trazer os imigrantes e disponibilizar os conhecimentos mais avançados, pois, em geral, ainda no princípio do século XX, a arte de fazer vinhos ou indústria da vinificação compreendia um conjunto de procedimentos com causas não muito claras. Por essa razão nos artigos científicos divulgava-se a vitivinicultura, dando-se grande ênfase aos procedimentos relativos à fermentação. Para tanto, os artigos, os estudos e as transcrições de artigos científicos estrangeiros tinham como finalidade tornar conhecidas algumas instruções "indispensáveis àqueles, principalmente, que não podem com facilidade ou proveito recorrer aos autores...." ${ }^{17}$

Antes da divulgação desse fenômeno por Pereira Barreto e pelo Instituto Agronômico de Campinas, pouco se sabia sobre a relação entre Pasteur e os vinhos e, portanto, era comum designar o processo de fabrico de vinho apenas como vinificação. Graças às descobertas de Louis Pasteur sobre a natureza dos microrganismos, ou também fermentos, e sobre a influência da temperatura no processo, uma nova etapa de vinificação foi identificada. Com o princípio dessa divulgação, mais incisiva a partir de 1900, a vinificação que incluía várias tarefas na cantina tornou-se a vinificação moderna, relacionada à fermentação.

O vinho que não seguisse esses métodos era considerado "artesanal" ou "falsificado", notadamente quando havia fermentação incompleta ou presença de ácido acético, modificando o status do conceito artesanal anterior. Assim, recorrer à vinificação moderna era eliminar as incertezas, batalhas e mistérios do fabrico de vinho.

Antes, a fermentação fugia aos olhos e ao controle de quem fabricava vinho. Ela compreendia apenas os procedimentos de esmagar, colocar nos tonéis, trasfegar uma, duas, três vezes para obter determinado gosto, aroma e corpo do vinho.

Cabia, assim, aos artigos científicos reforçar a necessidade de se observar a fermentação, apresentar em que ela consistia e as formas de controlá-la. Nesta nova etapa, novos instrumentos, novas medidas e novos agentes causadores da transformação do suco de uva em vinho foram identificados nos periódicos científicos. Nos artigos consultados encontramos diversas ilustrações para exemplificar as fases do processo ou mesmo para evidenciar algum instrumento. 


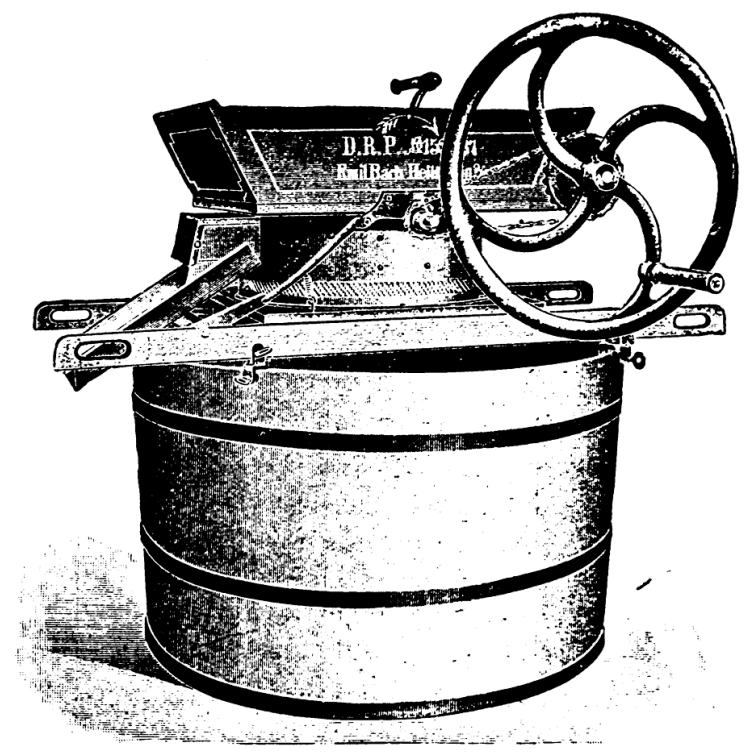

Figura 1 - Máquina E. Bach alemã, que pertencia ao Instituto Agronômico. Boletim do Instituto Agronômico de Campinas, 1909.

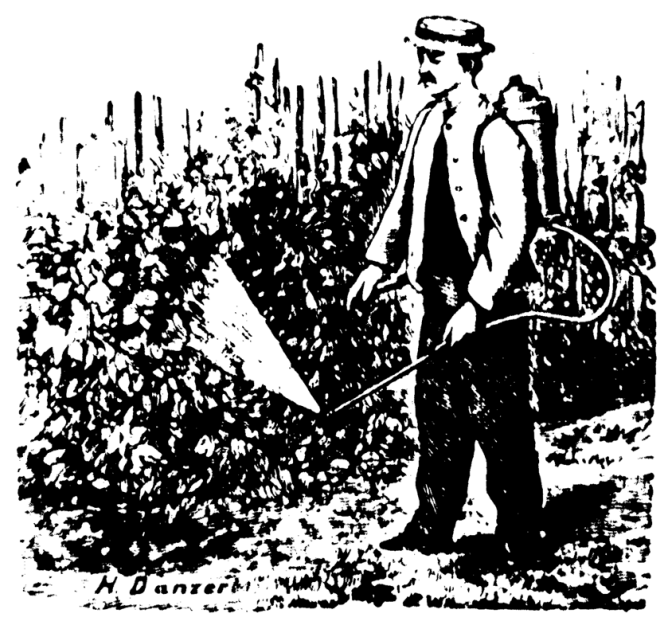

Figura 2 - Pulverizador. Relatório Agrícola do

Instituto Agronômico de Campinas do ano de 1915. 
Seguir esses procedimentos era tornar-se moderno. Por moderno, entendia-se o surgimento de "uma nova era. Podemos ser homens do nosso tempo, podemos afirmar a nossa emancipação enológica”. ${ }^{18}$ A vinificação moderna representava uma técnica, segundo o termo da época, pela qual o homem poderia dominar mais facilmente a natureza. Acreditavam que o vinho poderia ser produzido em qualquer clima do mundo, independentemente da casta da videira, do terreno, da riqueza do açúcar no mosto, mas principalmente pela qualidade do fermento. Por esse motivo, o agricultor moderno deveria estar apto para separar os procedimentos agrícolas dos industriais.

De forma semelhante à propaganda de Luís Pasteur na França, em relação às enfermidades da produção animal, o laboratório científico foi sendo identificado como o local necessário para que a agricultura e a pecuária se industrializassem, ou ganhassem maior escala. ${ }^{19}$ Por aqui, a independência da natureza significava a independência do trabalho agrícola, criando um debate no pensamento econômico brasileiro entre aqueles que defendiam as indústrias naturais e as artificiais, que excluíam as agroindústrias. ${ }^{20}$

Na produção açucareira, em fins do século XIX, também se defendeu essa separação, criando-se as centrais açucareiras. Mas, rapidamente essas centrais foram convertidas em usinas de açúcar, incorporando novamente a parte agrícola. Mesmo assim, no caso da agroindústria canavieira paulista, que esteve mais diretamente ligada ao capital cafeeiro e recebeu a atenção do Instituto Agronômico de Campinas desde o início do século XX, foi somente num momento de crise que a tecnologia agrícola foi inserida como uma forma de incremento produtivo, em fins da década de $1920 .{ }^{21}$

Desse modo, não é possível tomar o que era divulgado nos diversos artigos publicados em periódicos como o retrato do que se fazia. Também é muito difícil caracterizar a produção como se fazia, porque o discurso era de crítica e, por vezes, preconceituoso, por parte dos cientistas em relação aos vitivinicultores. Além disso, é por ocasião das crises do café, ou seja, quando da diminuição da importação de vinhos nobres e aumento no consumo dos vinhos comuns, que se nota um número crescente de localidades vinícolas requisitando o serviço do Instituto Agronômico de Campinas.

Nessas requisições estão contidas as preocupações para remediar os estragos cometidos por doenças e a busca por variedades mais produtivas e resistentes. Sem a continuidade dos trabalhos culturais nos momentos de expansão do café, os vinhedos feneciam, deixando de dar frutos em determinada quantidade e qualidade. E assim como ressaltava Adolpho Cavalcanti ${ }^{22} \mathrm{em}$ fins do século XIX, estaria uma "população superior" fadada a se entregar às beberagens e às falsificações, ou aos vinhos inferiores importados, que apesar 
de menor custo individual tiveram seu consumo aumentado nas décadas iniciais do século XX. E, no processo de institucionalização das ciências agrícolas, as instituições científicas primaram em estabelecer pesquisas em relação ao que se fazia no exterior, para aos poucos notarem os problemas locais e constituir soluções agronômicas próprias e que atendessem também aos pequenos e médios produtores. ${ }^{23}$

MUDANDO O FOCO DA LENTE CIENTÍFICA:

DO VINHO FALSIFICADO AO VINHO REGULADO

O vinho é feito somente com uva e necessariamente participará das boas ou más qualidades desta... sendo fácil que um vinhateiro descuidado ou ignorante fabrique mal o vinho com uma excelente uva, mas é de todo impossível fabricá-lo bom com uma uva má.

Barreto, 1900b, p.15

Entretanto, apesar da ênfase nos trabalhos industriais, restava uma dúvida: de qual uva deveria ser feito o vinho paulista, americana ou européia? No Brasil não há nenhum exemplar nativo do gênero Vitis, todas as videiras aqui plantadas foram espécies trazidas de outros continentes. Dentro da família das Vitaceas, o Brasil apresenta apenas exemplares de outros gêneros, cujos frutos não são comestíveis. ${ }^{24}$ Sem que o Brasil tivesse um único exemplar natural de uvas próprias para a vinificação, as discussões científicas e entre as elites encontravam-se num dilema.

Tal dilema era proveniente da classificação botânica dada às espécies de videira. Era comum acreditar que todas as variedades existentes descendiam de um único tipo europeu a Vitis vinifera Linn. Mas Asa Gray, importante botânico na época, reconheceu mais quatro espécies nativas da América do Norte: Vitis Labrusca, Vitis aestivalis, Vitis codifolia e Vitis vulpina.

Nas publicações encontramos, de um lado, um discurso 'eurocêntrico' a respeito das descendências das variedades, no qual todas as variedades descenderiam da espécie Vitis vinifera Linn.; de outro, o discurso 'americano', afirmando a 'independência' das origens das espécies americanas. ${ }^{25}$ Contudo, a partir do momento em que se afirmou a 'independência' dessas espécies, foi necessário também propor a independência dos vinhos produzidos com essas uvas de espécies americanas. Era preciso provar que ele era tão bom quan- 
to o tradicional vinho europeu. Por ocasião de uma exposição de vinhos na Filadélfia, em 1879, dizia-se que o vinho americano "não era mais que uma beberagem medonha, que o paladar europeu não poderia aceitar como potável". ${ }^{26}$ Enólogos do mundo inteiro buscavam classificar o vinho produzido com uvas nativas da América do Norte, tornando-o conhecido pelo gosto semelhante ao do cassis e de aroma semelhante ao da catinga da raposa, fedor do percevejo ou ainda foxy.

Desse modo, se acatassem as vides americanas, incitavam ao aumento dos vinhos propensos à acetificação, portanto, o vinho falsificado de acordo com a vinificação moderna, de gosto não tradicional e não muito aceito pelos especialistas. Se acatassem as européias, que não resistiam ao calor dos trópicos mas tinham maior teor de açúcar que as americanas (matéria-prima fundamental para a fermentação), a produção não apresentaria escala para ser comercializada para todas as classes.

Para Pereira Barreto, em 1896, a hibridização entre as variedades seria algo semelhante à mestiçagem humana: "E assim como o cruzamento da raça caucásica com a raça negra tem dado por toda a parte produtos valetudinários, de uma debilidade extrema que se extinguem na quarta geração.... ${ }^{27} \mathrm{~Pa}$ rece nítido nesse trecho que as videiras européias estão para os homens de cor branca como as videiras americanas para os índios, negros e mulatos. Por outro viés, nota-se que Pereira Barreto compreendia a miscigenação como algo impróprio à evolução da raça branca e civilizada.

O conflito entre européias e americanas, entre tradicionais e progressistas, manteve-se durante todo o período, como entre Nicolau Vergueiro e Pereira Barreto, ou entre Amador Bueno da Cunha e Celeste Gobato, na década de 1930. Conseqüentemente, tratava-se de aceitar ou não a hibridização de variedades, indicando um tipo de videira mais produtiva para cada local, um problema da parte agrícola da produção, bem como as maneiras pertinentes de consertar seu vinho.

Desse debate, baseando-se em análises químicas realizadas no Instituto Agronômico de Campinas, foi se constituindo a expressão 'vinho regular', nem tão bom quanto o importado nem tão ruim, em gosto e conservação, como as falsificações e alguns vinhos nacionais produzidos com vinhas americanas. Antes de 1930, é recorrente encontrarmos na literatura a seguinte opinião de pesquisadores sobre a produção de vinho paulista: "É difícil encontrar vinho nacional que não seja acetificado. É necessário... indicar aos interessados... [a] correção do mosto, boa fermentação, emprego de fermentos especiais, boas condições de conservação" ${ }^{28}$ Trata-se ainda de um problema in- 
dustrial, não tão ligado à parte agrícola, requisitando a compra de equipamentos e maquinários que certificassem o momento exato e as características químicas da fermentação.

Mas também notamos, em alguns artigos, como esses problemas químicos passaram a ser contornados, geralmente, pela adição de açúcar ou com o chamado 'corte', pela adição de água em determinado momento da fermentação, ou ainda pela adição do vinho riograndense. Ao contrário do que afirma Wilson Cano, ${ }^{29} \mathrm{o}$ vinho riograndense já 'infestava' os mercados paulistas bem antes de 1930, vindo por transporte de cabotagem, chegando a Santos e ao Rio de Janeiro. Outra prática comum parece ter sido a compra de vinhos de várias cantinas por negociantes. Compravam na torneira antes do término da fermentação, causando, por vezes, transtorno nas ferrovias com o estouro de uma quartola pela liberação de gás carbônico. ${ }^{30}$

Com o entendimento dessas adaptações na literatura científica, começava aos poucos a se distinguir o vinho inferior da verdadeira falsificação ou fraude. As fraudes consistiam em vender "gato por lebre", como um vinho de jabuticaba por vinho de uva. Ou então, pela composição de um vinho pela adição de álcool no suco de uvas ou de outras frutas, que não fosse aquele obtido pelo processo de fermentação da própria fruta, ou da adição de água para que o produto rendesse mais já depois de envasado.

Como depôs um imigrante italiano, sob a suspeita de fraudar vinho, "O vinho progresso que o bebessem os tolos e bebia outros que enumerou na sua defesa". ${ }^{31}$ Disse isso porque buscava ser reconhecido como um burguês enriquecido. Isto é, diante da possibilidade de limpar seu nome pela retirada da acusação, não se incomodou em reforçar seu poder monetário nomeando os vinhos que consumia.

Rompe-se definitivamente com a antiga idéia de que o vinho dava status ao seu produtor, quando o consumo de vinho vinculava-se a uma atividade lucrativa. Já em fins da primeira década, o vinho dá lucros, sendo vendido em lojas de secos e molhados, em botequins ou em lojas de artigos importados. Seu consumo é feito individualmente ou em grupo, para embriagar-se, satisfazer uma vontade específica de vinho ou simplesmente comprar um líquido para beber.

O sr. Artur De Vecchi não precisava provar ele mesmo de seu vinho para lhe garantir a qualidade ou seu poder monetário. Essa produção lhe dava dinheiro, que lhe garantia o nome, através da corrupção judiciária. Quando pobre, fabricara e vendera um líquido falsamente com o nome de vinho, lembrando-se no seu depoimento com pavor desses tempos, em que fabricava 
com água, álcool e açúcar e bagas de sabugueiro algumas quartolas de vinhos por mês.

Através das variações na produção, entre a 'falsificação' e a 'fraude', alguns imigrantes puderam estabilizar-se no ramo, atendendo às populações de São Paulo e Campinas, com todas as qualidades de vinhos e de preços. Grande parte do incentivo ao consumo e à produção de vinhos pode ser lida nos textos, sem autoria, publicados nas revistas O Campo e Chácaras e Quintaes, a partir das décadas de 1910 e 1920 . Nesses artigos nota-se maior cuidado na divulgação científica para pequenos e médios vitivinicultores. Mesmo assim, tinham por base científica a vitivinicultura moderna inicialmente divulgada por Pereira Barreto e pelo Instituto Agronômico de Campinas. Tal produção e seu crescimento dentro de um gênero específico - divulgação científica - teve também seu auge na capital federal na mesma época. ${ }^{32}$

E se nem todos foram fabricantes de vinho, foi através do comércio em geral que alguns imigrantes tornaram-se parte da burguesia urbana, exercendo outras profissões e participando do processo de industrialização. Alguns teriam partido da importação para a fabricação, por exemplo, a do vinho. ${ }^{33}$ Se era questão de gosto ou de bolso não podemos precisar, mas sabemos que o mercado apresentava uma grande variedade de produtos vendidos sob o nome de vinho.

Tornou-se comum, na década de 1920, vincular o vinho à noção de saúde, pela venda de vinhos quinados, gemados, fortificados e medicinais. Marcava a sua presença o discurso 'normatizante' ou higiênico, pretendendo transformar uma nação de beberrões e embriagados em uma de trabalhadores fortificados. A necessidade de uma bebida sã, que não provocasse doenças e até mesmo o alcoolismo, também esteve presente nos jornais operários na mesma época.

Nesses periódicos, patrões e operários compartilhavam a mesma noção de saúde, que em parte anulava a dicotomia entre classes, mas, contraditoriamente, acabou solidificando um tipo de conhecimento científico e legitimando ideais e ações da classe capitalista, sendo comum o repúdio ao alcoolismo entre ambas as classes. ${ }^{34} \mathrm{Tal}$ conhecimento buscava critérios científicos para determinar o que era vinho; fora dessa margem as demais produções, que disputavam espaço no mercado, eram tidas como maléficas. Tal como apontou Ricardo Luiz Souza, ainda parecia haver uma relação entre o grau alcoólico das bebidas e a classe social, especialmente nos momentos de disputa pelo mercado.

É nesse contexto que se criou o Regulamento Nacional de Vinhos, em 
1933. Nele os vinhos medicinais, fortificantes e tonificados eram compreendidos como variações possíveis do vinho inferior. ${ }^{35}$ Foi a partir dessa regulamentação, que ainda indicava os mesmos parâmetros da vinificação moderna, que toda uma diversidade de vinhos e técnicas realizadas foram legitimados. Por exemplo, o uso de cera para determinar a temperatura no processo de fermentação, em lugar do termômetro. Após o regulamento, para cada classe de vinho havia um limite do teor de acidez e, assim, a falsificação que era apontada pelos especialistas passou a ser determinada pelo Estado. Em 1935, também se decretou a obrigatoriedade de certificado de inspeção para despacho e livre curso nas empresas de transporte, sob a taxa de 25 réis por litro aos vinhos de todas as classes produzidos no estado de São Paulo.

Desse modo, diferentes tipos de vinhos - como os açucarados, os vermutes e o próprio suco de uva - passaram a ser fiscalizados e puderam circular no mercado. Ao contrário do consumo da cachaça, beber um vinho nacional tornou-se uma prática socialmente reconhecida, mesmo que ela não alcançasse o paladar buscado pelas "classes superiores", acostumadas aos vinhos importados. Nota-se também em alguns rótulos o costume de datar o ano de fundação da vinícola ou da marca, para dar maior legitimidade ao produto.

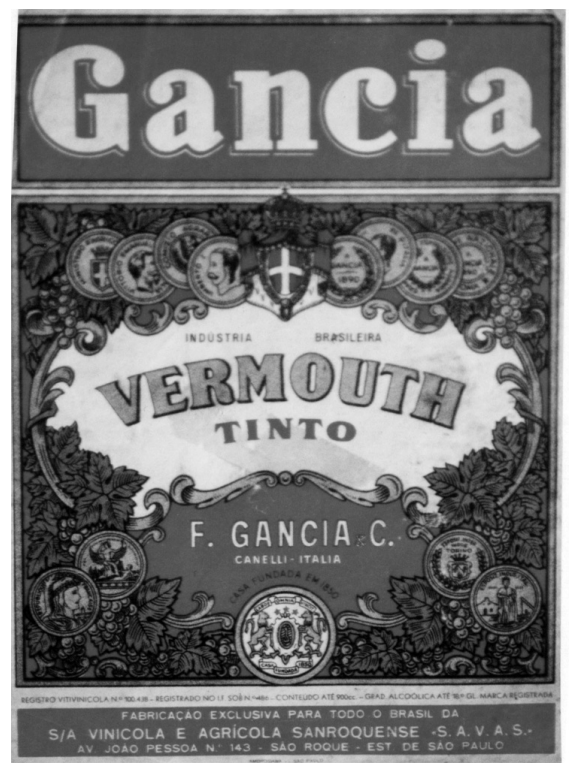

Figura 3 - Vermuth tinto Gancia, S/A - Vinícola e agrícola Sanroquense, sob a marca de F. Gancia C., casa fundada em 1850, Canelli - Itália. 


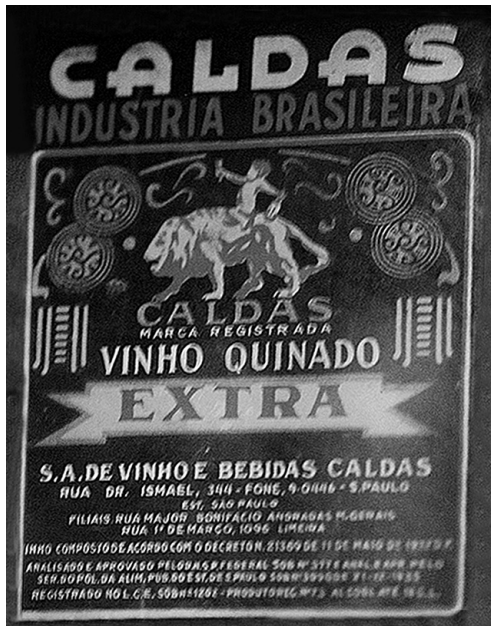

Figura 4 - Vinho Quinado Extra, S.A., de Vinho e Bebidas Caldas.

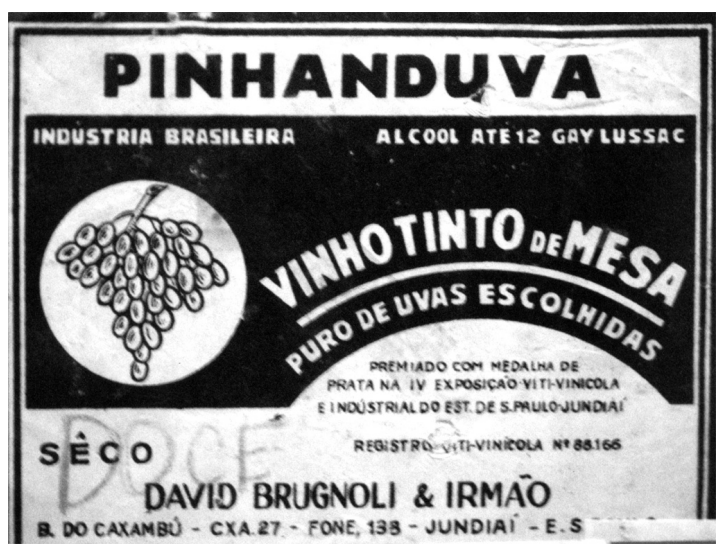

Figura 5 - Pinhanduva, David Brugnoli \& Irmão, Jundiaí.

Como resultado da regulamentação, logo em seguida foram criadas Estações Experimentais nos principais centros vitivinícolas do estado, como Jundiaí e São Roque, bem como um posto de fiscalização do Ministério da Agricultura em Jundiaí. Assim, a partir de 1930 a vitivinicultura cresceria no estado de São Paulo, com a produção de uvas para consumo de mesa, para a produção de vinagre e também para a produção de vinhos. 


\section{CONSIDERAÇÕES FINAIS}

No período entre 1890 e 1930, foram amplamente divulgados e atrelados à questão racial novos conhecimentos sobre o vinho e a fermentação e sobre o papel transformador da ciência na sociedade. Entretanto, considero que o processo de surgimento, expansão e contração do espaço agrícola da videira deu-se muito mais em razão de fatores sociais gerais, como a expansão cafeeira e ferroviária e a consolidação de núcleos coloniais e cooperativas próximo aos grandes centros urbanos, do que de uma inserção efetiva desses conhecimentos na agricultura.

A divulgação científica efetuada nesse momento teve o papel de manter a possibilidade da vitivinicultura como uma alternativa, fazendo também sua propaganda. Porém, tendo a concordar com Lia Romero em que o desenvolvimento da policultura no estado ficou restrito às grandes lavouras como a da cana-de-açúcar, de citros e algodão, ou seja, àquelas que socialmente tinham condições para serem transformadas em agroindústrias, porque vinculadas ao grande capital.

Sob outro viés, também podemos compreender que a principal diferença entre fins do século XIX e a década de 1930 consistiu, a meu ver, na existência de recursos humanos formados e motivados para atender as demandas nacionais e locais. Mesmo que os títulos de agrônomo e engenheiro agrônomo fossem comuns entre os filhos de grandes cafeicultores, a partir da década de 1920, época da expansão agrícola e demográfica, alguns filhos de imigrantes também foram estudar agronomia, trazendo outras motivações.

Considero, portanto, que foi a manutenção desses espaços da ciência e de um debate científico nas publicações, a criação de um mercado local, bem como o início da identificação de problemas agronômicos próprios, que motivaram a criação de instituições científicas específicas para o setor. Estas passaram a realizar experiências de campo e laboratório, criando tecnologias que alavancassem o processo econômico. Assim, pelo viés da história das ciências foi possível compreender alguns aspectos históricos de uma produção agrícola de pequeno porte e observar como, por vezes, houve um impulso produtivo gerado e mantido na cultura científica.

Outro aspecto que merece destaque foi a necessidade de fundamentar historicamente a produção de vinhos a um discurso de constituição da nação progressista. No caso dos vinhedos paulistas, a ciência atuou de forma a universalizar a produção sob a batuta das leis naturais, baseando-se em conceitos como raça, cultura, mestiçagem e evolução. Acreditava-se que a tecnolo- 
gia permitiria a produção do vinho europeu em todos os lugares, com resultados idênticos.

O trabalho de caráter histórico realizado por Júlio Inglez de Souza ainda se enquadra nesse viés. Ao fazer o levantamento das origens dos vinhedos paulistas, esse autor dá subsídios para consolidar a origem cultural da produção local e legitima um produto no mercado, como vinculado a uma cultura européia pela vinda e pela força persistente dos imigrantes. Trazendo essas questões para a atualidade, destaco que esse procedimento ainda está presente na comercialização dos vinhos nacionais e importados, por meio da criação dos selos de origem. Vale, então, lembrar que ao bebermos um vinho nacional ou importado, nos seus diferentes tipos, procedências e preços, estamos também evocando determinados conceitos sociais e estabelecendo vínculos culturais com a nossa sociedade.

\section{NOTAS}

${ }^{1}$ SOUZA, Ricardo. Cachaça, vinho, cerveja: da Colônia ao século XX. Revista de Estudos Históricos, Rio de Janeiro, n.33, 22p., 2004.

${ }^{2}$ Cf. SANTOS, J. V. T. Colonos do vinho: estudo sobre a subordinação do trabalho camponês ao capital. São Paulo: Hucitec, 1978.

${ }^{3}$ MONTEIRO, Rosane. Diversificação econômica das fazendas mistas no interior paulista: produção voltada para o mercado interno, 1889-1920. Anais eletrônicos do V Congresso Brasileiro de História Econômica e $6^{a}$ Conferência Internacional de História de Empresas. Caxambu (MG): ABPHE, 7 a 10.09.2003.

${ }^{4}$ ROMERO, Lia. A vitivinicultura no estado de São Paulo (1880-1950). Dissertação (Mestrado) - Instituto de Economia, Unicamp, Campinas, 2004; BORCOSQUE, L. A. La vitivinicultura en el estado de San Pablo (Brasil): Instauración y desarrollo de la producción vitivinícola en el período de 1880 a 1930. (Primera parte). Universum, v.20, n.2, p.268-287, 2005.

${ }^{5}$ Cf. DANTES, Maria. (Org.). Espaços da ciência no Brasil, 1800-1930. Rio de Janeiro: Ed. Fiocruz, 2001.

${ }^{6}$ Agradeço ao prof. dr. Héctor Hernán Bruit do Instituto de Filosofia e Ciências Humanas da Unicamp (in memoriam) pela orientação de iniciação científica e à Fapesp pela concessão de bolsa (processo n. 97/07850-5). Uma versão preliminar deste artigo foi apresentada oralmente no III Encontro de Filosofia e História da Ciência do Cone Sul (AFHIC), 24 a 30.05.2002.

${ }^{7}$ KIDDER, Daniel. Reminiscências de viagens e permanências na Província do Sul do Brasil, 
Rio de Janeiro e São Paulo. Compreendendo notícias históricas e geográficas do Império e das províncias. Belo Horizonte: Itatiaia, 1980 (1845), p.227.

${ }^{8}$ MONBEIG, P. Pioneiros e fazendeiros de São Paulo. São Paulo: Hucitec; Polis, 1984. p.133.

${ }^{9}$ Cf. GOUBERT, Jean. A divina garrafa: viagens, alcoóis e remédios nos dois hemisférios dos séculos XVI ao XX. História, Ciências, Saúde-Manguinhos, v.8, supl., Rio de Janeiro, 2001.

${ }^{10}$ TEIXEIRA, Luís. Da transmissão hídrica a culicidiana:a febre amarela na sociedade de medicina e cirurgia de São Paulo, Revista Brasileira de História. São Paulo, v.21, n.41, p.217242. 2001. p.220.

${ }^{11}$ Cf. HOCHMAN, Gilberto. A Era do Saneamento: as bases da política de saúde pública no Brasil. São Paulo: Hucitec/Anpocs, v.1, 1998.

${ }^{12}$ Cf. LUCA, Tânia de. A Revista do Brasil: um diagnóstico para a (N)ação. São Paulo: Ed. Unesp, 1999.

${ }^{13}$ Cf. SILVA, Márcia. O ensino médico em debate: São Paulo, 1890-1930. História, Ciências, Saúde - Manguinhos, Rio de Janeiro, v.9, supl., p.139-159, 2002.

${ }^{14}$ BARRETO, Luís Pereira. A vinificação moderna. São Paulo: Ed. Red. da Revista Agrícola, 1900a. p.15.

${ }^{15}$ FIGUEIRÔA, S. F. de M.; LOPES, M. M. A difusão da ciência e da tecnologia através da imprensa e dos periódicos especializados (1890-1930). In: Annais do VI Seminário Nacional de História da Ciência e da Tecnologia, Rio de Janeiro, v.1, p.190-195, 1997. p.192.

${ }^{16}$ CONDIÇÕES adoptadas nos contratos de colonos para a cultura de café, vinha e canna de assucar. Campinas (SP): Typ. Livro Azul, 1888. (Centro de Memória Unicamp).

${ }^{17}$ D'UTRA, Gustavo. Tratamento do mildio e o do oidio das videiras. Boletim do Instituto Agronômico do Estado em Campinas, 1899. p.588.

${ }^{18}$ BARRETO, Luís Pereira. A arte de fabricar o vinho: manual do vinicultor. São Paulo: Ed. Red. da Revista Agrícola, 1900b. p.118.

${ }^{19}$ Cf. LATOUR, Bruno. Dádme un laboratório y moveré el mundo. In: Iranzo, Juan M. et al. (Comp.). Sociologia de la ciencia y la tecnologia. Madrid: Consejo Superior de Investigaciones cientificas, 1995. p.237-257.

${ }^{20}$ Cf. ABREU, Marcelo. A ordem do progresso: cem anos de política econômica republicana (1889-1989). Rio de Janeiro: Campus, 1989.

${ }^{21}$ OLIVER, Graciela; SZMRECSÁNYI, Tamás. A Estação Experimental de Piracicaba e a modernização tecnológica da agroindústria canavieira (1920 a 1940). Revista Brasileira de História, São Paulo, v.23, n.46, p.37-60, 2003.

${ }^{22}$ CAVALCANTI, Adolpho. A viticultura em São Paulo. Boletim do Instituto Agronômico do Estado em Campinas, 1898. p.24.

${ }^{23}$ OLIVER, G. de S. O papel das escolas superiores de agricultura na institucionalização das 
ciências agrícolas no Brasil, 1930-1950: práticas acadêmicas, currículos e formação profissional. Tese (Doutorado) - Unicamp, Campinas, 2005.

${ }^{24}$ Agradeço ao prof. dr. Júlio Lombardi (Unesp/Rio Claro) as informações sobre as Vitaceas nativas do Brasil.

${ }^{25}$ DA VIDEIRA, sua origem, história, conveniência e sua cultura e variedades preferíveis. Revista de Horticultura, Jornal de Agricultura e Horticultura Prática, 1876. p.52.

${ }^{26}$ Idem, p. 51.

${ }^{27}$ BARRETO, Luís Pereira. Viticultura no Brasil, Revista Agrícola, Órgão da Sociedade Pastoril e Agrícola, Anno II, 1896, p.34.

${ }^{28}$ Artigo da Secção de Chimica e Tecnologia Agrícola, Relatório do Ano Agrícola 1930-1931, p. 122 .

${ }^{29}$ CANO, Wilson. Desequilíbrios regionais e concentração industrial no Brasil: 1930-1970. São Paulo: Global, 1985. p.57.

${ }^{30}$ A VITICULTURA nacional. Chácaras e quintas, jul. 1929, p.54-5.

${ }^{31}$ Revista Parafuso, abr. 1919, n.142. (Arquivo Edgard Leuenroth).

${ }^{32}$ Cf. MASSARANI, Luísa; MOREIRA, Ildeu. A divulgação científica no Rio de Janeiro: algumas reflexões sobre a década de 20. História, Ciências, Saúde - Manguinhos, Rio de Janeiro, v.7, n.3, p.627-651, 2001.

${ }^{33}$ DEAN, Warren. A industrialização de São Paulo (1880-1945). São Paulo: Difel, 1971. p.60.

${ }^{34}$ Cf. BERTUCCI, L. M. Saúde: uma arma revolucionária. São Paulo: Campinas/CMU/Unicamp, 1997.

${ }^{35}$ UNIFICAÇÃO dos regulamentos fiscais sobre fomento, defesa e fiscalização da produção, circulação e exportação dos vinhos nacionais. O Campo, 1933, p.45-49.

Artigo recebido em maio de 2007. Aprovado em dezembro de 2007. 